\title{
PASAJES SONOROS [Y RUIDISTAS] DE LA CIUDAD FUTURISTA
}

\author{
Juan Agustín Mancebo Roca \\ Universidad de Castilla-La Mancha. Dpto. Historia del Arte
}

\section{Resumen}

Con las parole in libertà el futurismo italiano incorporó a la poesía los sonidos de las máquinas y las muchedumbres de la ciudad contemporánea, pasajes sonoros que se desplazarían del mismo modo a la experiencia musical. Pratella compondría una música que buscaba reflejar el dinamismo de las nuevas ciudades. En El arte dei rumori Luigi Russolo consideraría el sonido como una entidad modificable que se podría estructurar como si se tratase de música clásica. En la onomolingua Fortunato Depero investigaba nuevas formas de expresión para representar los sonidos naturales y urbanos. En los años veinte, Francesco Casavola y Silvio Mix abandonarían el experimentalismo de Russolo y Pratella pero continuarían explorando los recursos sonoros urbanos en su trabajo. La abstracción de las síntesis para radio, vinculadas a las masas y a la guerra, concluirían la experiencia de los paisajes urbanos del futurismo.

\section{Palabras clave: FUTURISMO; CIUDAD; SONIDO; BELICISMO; MÚSICA}

\section{SONOROUS [AND NOISY] PASSAGES OF THE FUTURISTIC CITY}

\section{Abstract}

With parole in libertà, Italian futurism incorporated into poetry the sounds of machines and the crowds of the contemporary city, sonorous passages that would also shift into the musical experience. Pratella composed music to reflect the dynamism of the new cities. In The Art of Noises, according to Luigi Russolo, sound is a modifiable entity that could be structured as if it were classical music. Fortunato Depero investigated new forms of expression to represent natural and urban sounds in onomolingua. Francesco Casavola and Silvio Mix abandoned the experimentalism of Russolo and Pratella in the 1920s, they will, however, continue to explore urban sound resources in their work. The abstraction of radio syntheses, linked to the masses and to war, would bring Futurism's urban landscapes to a close.

Key words: FUTURISM; CITY; SOUND; BELLIGERENCE; MUSIC

\footnotetext{
Mancebo Roca, Juan Agustín. 2021. "Pasajes sonoros [y ruidistas] de la ciudad futurista". AusArt 9 (1): 127-142. D0I: 10.1387/ausart.22670
}

\section{AUSART}




\section{INTRODUCCIÓN}

La vida de antaño se basaba en el silencio. En el siglo XIX, con la invención de la maquinaria, el ruido había nacido. Hoy el ruido, reina y triunfa supremo sobre las sensibilidades del hombre.

Luigi Russolo

El futurismo italiano incorporó las imágenes y los sonidos de la metrópoli contemporánea a su plástica y a su literatura. Fascinados por la alteración sensitiva que los sonidos producirían en sus habitantes - primitivos de una nueva civilización mecánica- se focalizaron en los ruidos de las ciudades como un elemento sobre el que construir una nueva teoría musical. Este artículo estudia los pasajes sonoros de la metrópoli futurista y su incorporación a sus propuestas musicales, la creación de un arte de los ruidos, la verbalización del fragor metropolitano, la añadidura del sonido citadino a la música futurista en la segunda mitad del movimiento y a la extensión del concepto de la literatura sin hilos ejemplificada en la radio y las síntesis con sonidos de ciudades. El artículo concluye con el legado futurista en la música experimental contemporánea.

\section{UNA LITERATURA SONORA}

Publicado por Filippo Tommaso Marinetti en la primera página del diario parisino Le Figaro el 20 de febrero de 1909, Fondazione e Manifesto del futurismo establecía una nueva relación sensitiva con la metrópoli condicionada por los sonidos urbanos de los medios de transporte -tranvías, trenes y automóviles-. Como mantenía Luigi Russolo "con la invención de las máquinas nació el ruido" $(1916,9)$ y, lejos de la concepción tradicional de la ciudad, entendida por el futurismo como un espacio sin máquinas y por tanto silencioso, la urbe se convertiría en un organismo dinámico capaz de asimilar los nuevos elementos mecánicos que condenarían al olvido los murmullos y crujidos de las antiguas estructuras urbanas. Es paradigmático que la frase que reconoce y ejemplifica el futurismo: "un coche de carreras es más bello que la Victoria de Samotracia" sea una versión reducida que excluye al ruido: "los tubos del capó se comparan con serpenti dall'allito esplosivo y el coche de carreras es más exactamente un automobile ruggente". Por tanto, en el texto fundacional "la velocidad y el ruido son las principales cualidades resaltadas" (Solanas 
2011, 39). En este contexto la metrópoli se transfiguraba en un lugar de alerta permanente en el que sonidos y ruidos provocarían una nueva excitación sensorial en el sujeto contemporáneo.

Cuando los futuristas intentaron elaborar un programa artístico coherente con el mundo mecánico, la visualidad y la sonoridad se incorporarían a su literatura con la premisa de liberar a la palabra de su anclaje tradicionalista como proclamaba Distruzione della sintassi. Immaginazione senza fili. Parole in libertà (11 de mayo de 1913). A este respecto el paroliberista Paolo Buzzi consideraba que el verso libre era un conjunto de ritmos que filtraban sensaciones musicales y permitirían una amplitud ilimitada de invenciones y hallazgos fonéticos: "la palabra -escribe Buzzi- está aislada en el espacio como una estrella. La parte gráfica y aquella pictórica, como la parte onomatopéyica, pertenece a la música" $(1988,36)$. Para los futuristas el poema era un violento alegato que debía incorporar elementos de otras disciplinas y la sonoridad de la palabra se transformaría reacondicionando el formato clásico del libro que ya no era únicamente "un artefacto lingüístico, sino también una compleja máquina visual" (Ghignoli 2011, 42).

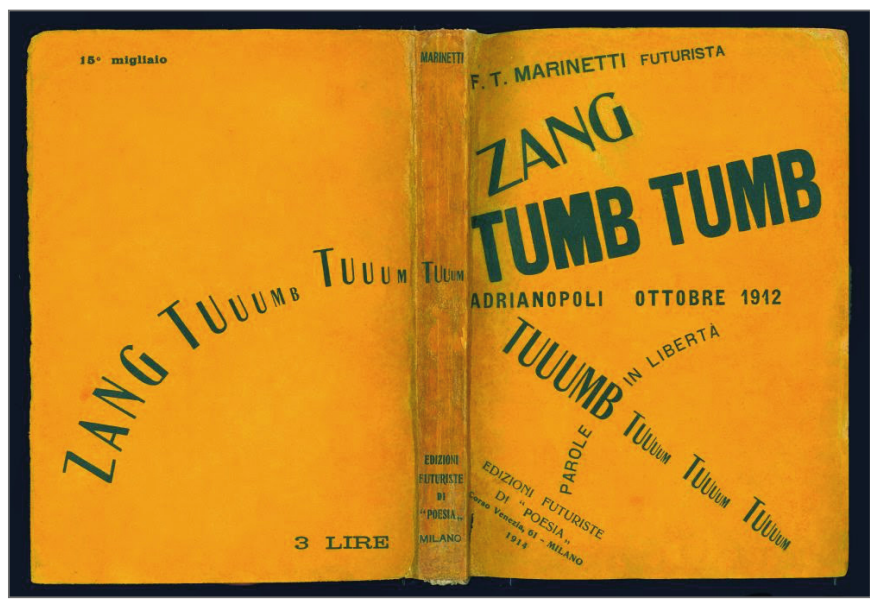

Filippo Tommaso Marinetti, Zang Tumb Tumb, 1914. Edizioni Futuriste di "Poesia", Milán,

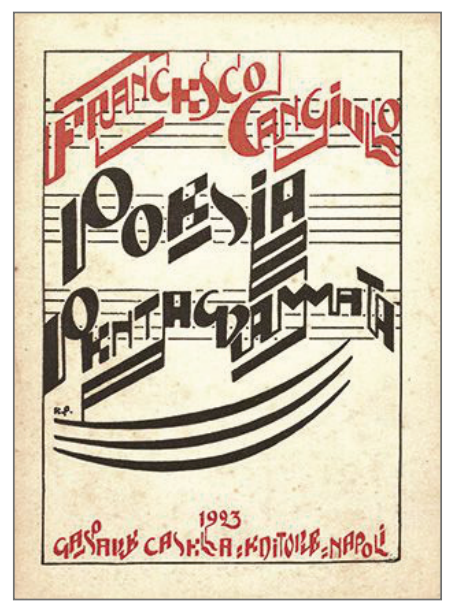

Francesco Canguillo, Poesia pentagrammata, 1923. Gaspare Casella Editore, Nápoles.

El componente acústico estructuraría el volumen Zang Tumb Tumb (1914) y el capítulo "Parabola ed esplosione della bomba" en 8 Anime in una bomba (1919) de Marinetti, que configuraban una dialéctica de la explosión que se filtraría en las experiencias paroliberas de Folgore, Meriano, Volt, Soffici, Buzzi, 
y Govoni entre otros. Mención aparte merecen los poemarios Guerrapittura de Carlo Carrà (1915) y Poesia pentagramatta de Francesco Cangiullo (1923). Carrà exploraba la plurisensorialidad apuntada en su manifiesto La pittura dei suoni, rumori, odori (11 de agosto de 1913) proponiendo la incorporación del ruido a la pintura ${ }^{1}$ y Cangiullo concebiría un pentagrama intervenido por las parole in libertà que enfatizaba la sonoridad del poema. Como señalaba Luciano Carsuso, Poesia pentagramatta "resuelve el importantísimo problema de la polifonía actual en la poesía parolibera, llegando a conferir el tiempo a los sonidos de las onomatopeyas y al ruidismo" $(1979,10)$. El futurismo incorporaba no solo los elementos vinculados a la transformación del sujeto contemporáneo "sino la introducción de los ruidos de la vida moderna en la propia literatura” (Solanas 2011, 64).

\section{UNA MÚSICA URBANA: BALILLA PRATELLA}

Fondazione e manifesto del futurismo nuclearizó a los artistas italianos que buscaban renovar una cultura que solo miraba al pasado. Al incipiente movimiento se fueron incorporando artistas que desarrollarían textos programáticos en las diferentes disciplinas artísticas.

En el caso de la música, Marinetti elegiría al compositor Francesco Balilla Pratella para que concibiera una propuesta acorde con la sensibilidad de la máquina y la ciudad industrial (Lista, 2001: 135) incitándole a superar el simbolismo mediante una música "más que moderna, profética, liberada de cualquier nebulosidad, de mitos y leyendas, de la obsesión idílica agreste y las monerías erotómanas" (Hulten 1992, 527). Pratella, musicólogo de sólida formación, había sido discípulo de Pietro Mascagni y experimentaba con nuevos lenguajes partiendo del concepto de la maestría y la tradición. Pratella, en el fulgor de las proclamas, escribiría tres manifiestos: el Manifesto dei musicisti futuristi, el 11 de octubre de 1910; La musica futurista: Manifesto técnico, el 11 de marzo de 1911 y La distruzione della quadratura, el 18 de julio de 1912.

En el primero establecía los parámetros que ponían en valor los sonidos de los entornos metropolitanos, la expresión de las multitudes, la industria y los medios de transporte: "la baraúnda humosa de los puertos mercantes, la grandeza de capitales agitadas y sus innumerables chimeneas de fábrica, se transforman en voces potentes y prodigiosas" (Pratela 1910, 4) buscando una 
experiencia condicionada por la máquina y la electricidad divinizadas por los actualistas italianos. En el segundo, que era una ampliación del anterior, consideraba el verso libre como el elemento que simbolizaba la libertad propia del futurismo que incorporado a la composición transcribiría el "alma musical de las masas, de los grandes centros industriales, de los trenes, de los transatlánticos, de los acorazados, de los automóviles y de los aeroplanos" (1911, 4). La distruzione della quadratura era un texto técnico que pretendía "crear el nuevo orden del desorden, destruyendo la cuadratura secular" (Hulten 1992, 527).

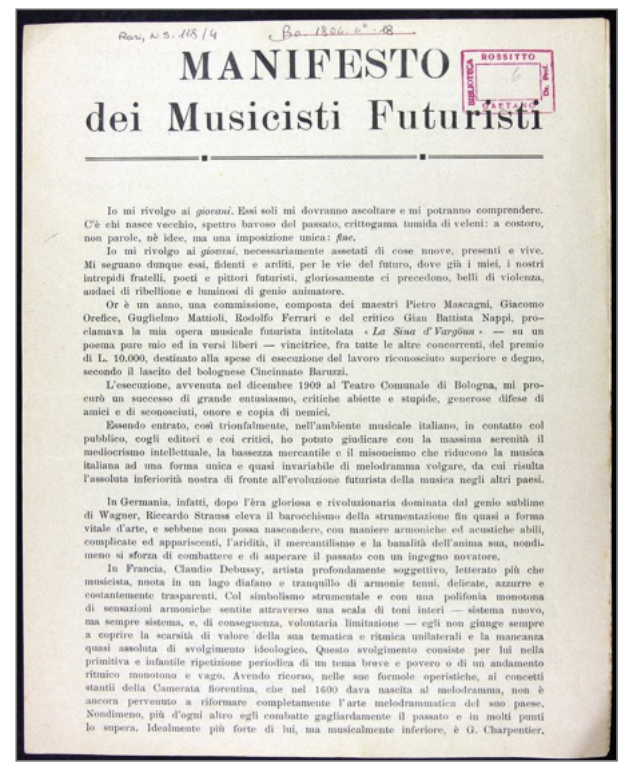

Balilla Pratella, Manifesto dei Musicisti Futuristi, 1910. Edizioni Futuriste di "Poesia”, Milán.

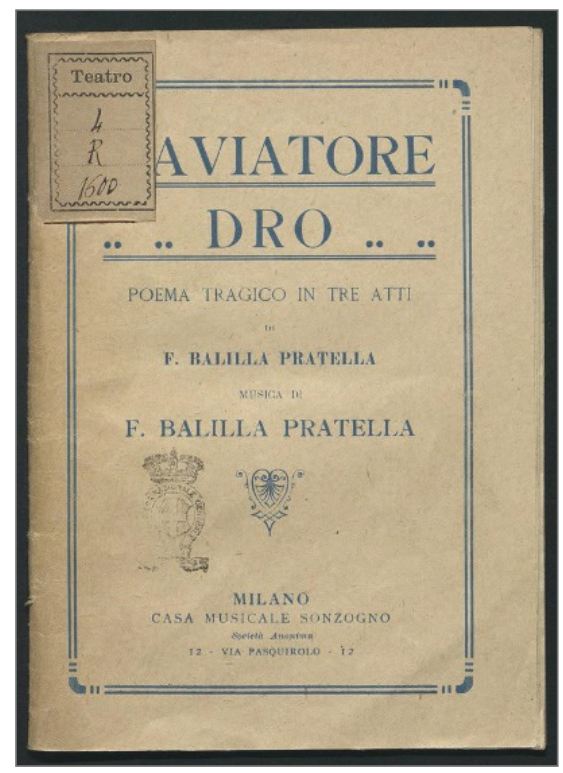

Balillia Pratella, L'aviatore dro. Poema Tragico in Tre Atti, 1920. Biblioteca Nazionale Centrale, Florencia.

Las afirmaciones de Pratella provocaron reacciones de todos aquellos que dudaban de la cualidad de la música futurista e incluso de su propia existencia. De hecho, su aserto relacional entre música, máquina y ciudad no era suyo, sino que era una aportación de Marinetti y su secretario Decio Cinti que tenían la última palabra sobre los manifesti: "algunas afirmaciones de carácter polémico y otras de carácter teórico referentes a las reacciones entre música y máquina no las escribí ni siquiera lo pensaba" confesaría en su autobiografía (citado en Lombardi 2009, 365). 
La concreción futurista de Pratella fue decepcionante al no intuir las transformaciones que preconizaba la vanguardia italiana. Musica futurista- Inno a la vita op. 32 -publicada por Bongiovanni, Bolonia, 1912, con portada de Boccioni- fue interpretada durante una serata el 21 de febrero en el teatro Costanzi de Roma y supuso el primer intento de hacer una música acorde con los sonidos de la ciudad, pero revelaba "la filigrana característica de su pensamiento musical, entre el lirismo y la inexpresividad" (Lombardi 2009, 365). Exceptuando los círculos vanguardistas, tuvo un rechazo unánime.

Su segunda pieza, L'aviatore Dro (1920), fue una ópera en tres actos de temática aérea que combinaba instrumentos tradicionales con los intonarumori de Russolo. Marinetti le pidió que incluyera los ruidos de un avión reclamándole "una música que fuera expresión de las grandes aglomeraciones humanas en las que la electricidad multiplique y complique las fuerzas" (citado en Lista 2011, 135). Pese a su audacia, L'aviatore Dro estaba impregnada del espíritu de la música del XIX, algo de lo que Pratella nunca consiguió desligarse en su militancia vanguardista. Sus resultados como músico futurista se consideran actualmente bastante modestos (Salaris 1992, 53).

\section{LOS RUIDOS DE LUIGI RUSSOLO}

Luigi Russolo reconocía que la experiencia de Pratella le llevó a una música que reflejaría las grandes metrópolis y el paradigma industrial e implementó una política ruidista a partir de su manifiesto L'arte dei rumori (11 de marzo de 1913) que tres años después se completaría en el libro homónimo editado por las Edizioni Futuriste di "Poesia".

Russolo había sido uno de los primeros pintores futuristas y había suscrito los manifiestos esenciales de la disciplina. Al contrario que Pratella no era músico profesional, aunque partía de una tradición simbolista relacionada con la música. Por otro lado, su padre era un compositor aficionado y sus hermanos Antonio ${ }^{2}$ y Giovanni habían estudiado en el conservatorio de Milán. De hecho, una de sus primeras pinturas fue La musica, expuesta en la muestra de abril de 1911 y que reapareció con el título Dinamismo musicale en febrero de 1913 en una muestra en el teatro Costanzi de Roma, momento en el que Russolo estaba confeccionando sus intuiciones ruidistas ${ }^{3}$. 


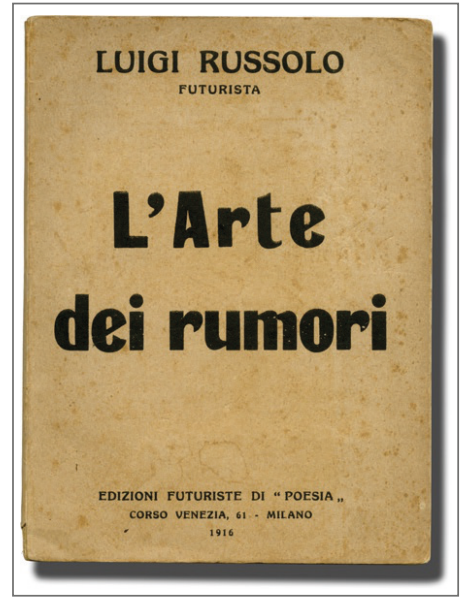

Luigi Russolo, L'Arte dei rumori, Edizioni Futuriste di "Poesia", Milán, 1916.

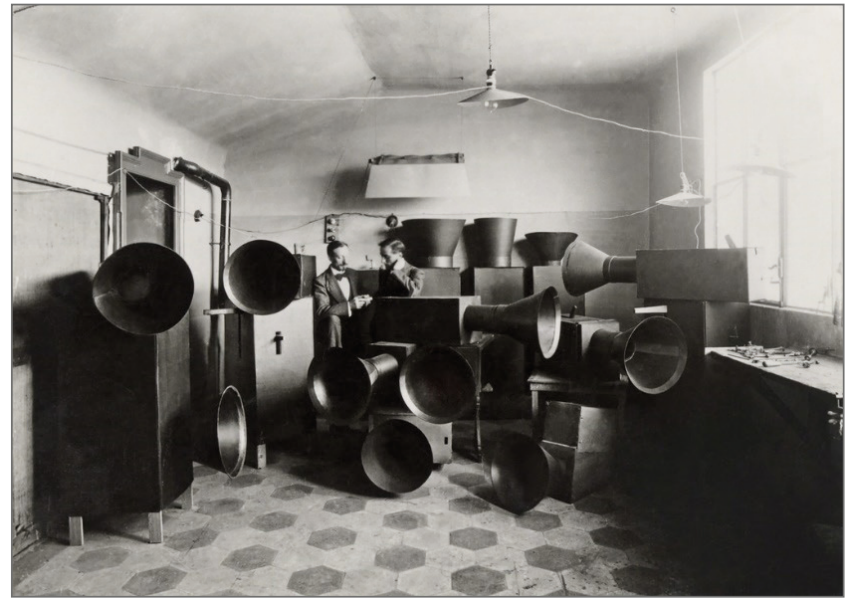

Luigi Russolo y Ugo Piatti en su estudio con los intonarumori, Milán, 1916.

Russolo trasladará las onomatopeyas paroliberas a la música y L'arte dei rumori conceptualizando una música derivada de la multiplicación de las máquinas "en las atmósferas fragorosas de las grandes ciudades" $(1916,10)$. Los ruidos constituían la evolución de la música pudiendo combinarse los sonidos de las máquinas y de las muchedumbres ${ }^{4}$. A partir de la publicación del manifiesto, Russolo abandonaría la pintura para dedicarse exclusivamente a los ruidos con la voluntad de renovarlo todo. Con la colaboración del también pintor Ugo Piatti desarrolló los intonarumiori -entonarruidos- instrumentos que recreaban los sonidos estridentes de las máquinas de la ciudad. Los intonarumiori consistían en una caja de resonancia que generaba ruidos mediante un altavoz que amplificaba los sonidos graduados por una manivela. También concibió una grafia enarmonica para explicar la notación musical de sus artefactos (ibíd., 67-71).

Luigi Russolo distinguía seis familias de ruidos que partían de la naturaleza y de la ciudad moderna y que la orquesta futurista reproduciría mecánicamente: estruendos, silbidos, susurros, estridencias, sonidos de percusión y voces de animales y de hombres con los que "los motores y las máquinas de nuestras ciudades industriales podrán un día ser sabiamente entonados, con el fin de hacer de cada fábrica una embriagadora orquesta de ruidos" (ibíd., 17). También, en la línea intervencionista del movimiento, dedicó un capítulo a los ruidos de la guerra (ibíd., 43-9). 
El 2 de junio de 1913 en la serata del Teatro Storchi de Módena se mostró el primer entonarruidos, un explotador que reproducía un motor de explosión cuyo diseño podía modificar gradualmente el sonido. En ese momento, Russolo tenía ultimados un crepitador, un zumbador y un frotador que posteriormente completaría con el resto de los instrumentos ruidistas.

El 21 de abril de 1914 presentaría en el teatro Dal Verme de Milán Spirali di rumori, con una orquesta de intonarumiori, en el que fueron interpretadas Il risveglio di una città -respuesta al cuadro de Boccioni La città che sale (1911) - Rumore di automobili e di aeroplani, Si pranza sulla terraza dell'hotel e Combattimento nell oasi, cuyo grado de experimentalidad supuso un "fiasco colosal" (Lombardi 2009, 366) provocando las acostumbradas algaradas entre futuristas y pasadistas. El concierto de Milán fue el prólogo a una larga gira de conciertos de intonarumiori por todas las capitales europeas. En su ímpetu por el reconocimiento de una música de ruidos por parte del capo futurista Maurice Ravel y Edgar Varese escucharon los intonarumiori en casa rosa de Marinetti en Milán que "colocaron a Russolo en una dimensión más artística que musical" (ibíd.). En cualquier caso, la teoría musical de Russolo era perfectamente coherente con las teorías de la metrópoli y de la máquina del movimiento futurista y "el hecho de encontrar nuevas fuentes sonoras en el mundo de las máquinas y de la vida moderna es quizá la operación más revolucionaria que el futurismo había producido hasta el momento" (Hulten 1992, 528).

\section{LA ONOMOLENGUA Y LAS LÍRICAS RADIOFÓNICAS DE FORTUNATO DEPERO}

La Onomalingua-verbalizacione astratta (1916) fue una variante de las parole in libertà, una poesía sonora visual, gestual y musical que derivaba "de la onomatopeya, del ruidismo, de la brutalidad, de las palabras en libertad futuristas" en la que Depero exploraba "los contenidos psíquicos de las sensaciones físicas" (Lista 2012, 237) y recreaba sonidos naturales y artificiales "ruidos creados por los hombres: bicicletas, tranvías, trenes, automóviles y todas las máquinas" (Depero [1934] 2012, 42). En la onomalingua, por tanto, la cualidad sonora de las palabras se descargaba sobre el papel. En Tramvai y Tramme reconstruía los ruidos estridentes del tranvía sobre las vías y los pensamientos se confundían con la estela del movimiento. Fiorillería- Aciaicia - Cristalizia (sensazioni di fiori-sensazioni de metalli- sensazioni di vetri) recreaba los rui- 
dos metálicos mecánicos producidos por los engranajes combinados con el cristal y elementos de naturaleza vegetal.

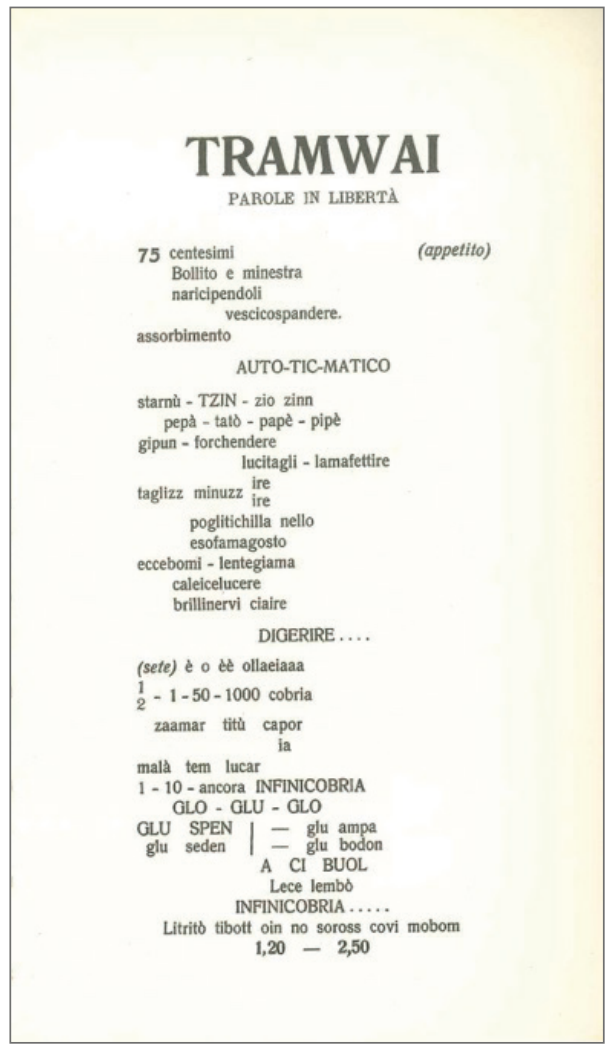

Fortunato Depero, Tramwai, 1916.

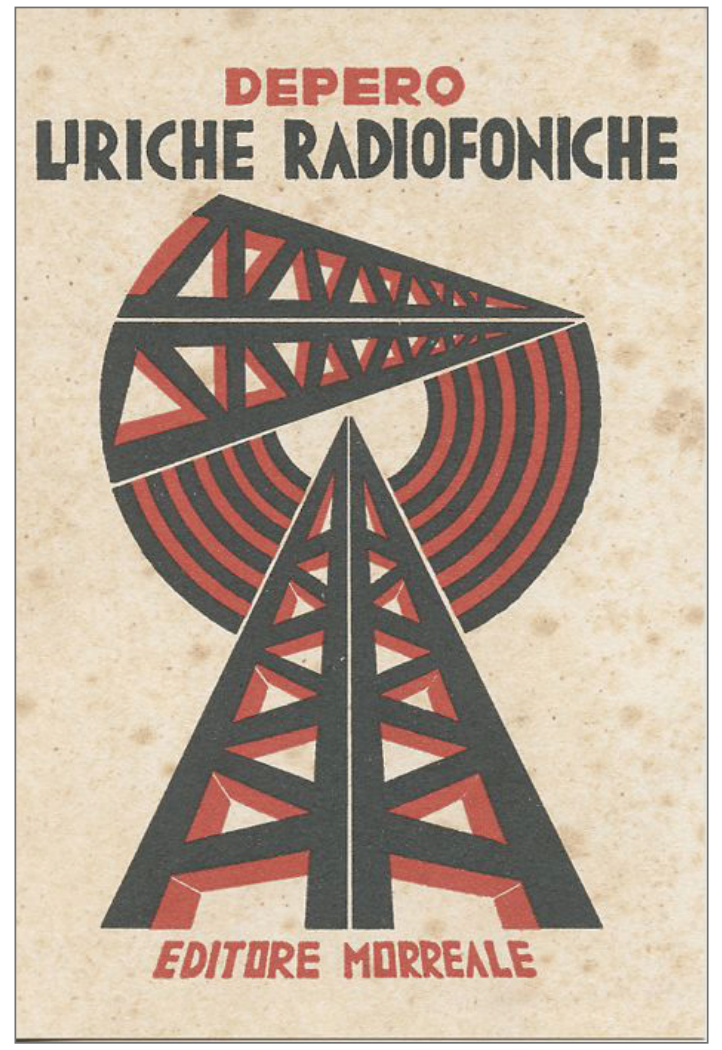

Fortunato Depero, Liriche radifoniche, Morreale, Milán, 1934.

En 1928, cuando viajó por primera vez a Nueva York, Depero quedó absolutamente fascinado con la ciudad puesto que simbolizaba todo aquello que había preconizado la vanguardia italiana. A este respecto, ideó un volumen parolibero y sonoro, New York- Film vissuto, que incluiría poemas sobre la imagen de Nueva York y recogería en dos discos las grabaciones de los ruidos de la metrópoli, pero no se llegó a realizar por falta de recursos.

Parte de ese material se utilizó en Liriche radifoniche (Radio Lyrics) editado por la milanesa Morreale, volumen con piezas sonoras para radio que buscaban contrastar con las emisiones radiofónicas comunes. Depero insistía en el prólogo en "la brevedad del tiempo, la variedad concisa de imágenes, sujeto 
contemporáneo, lirismo poético fundido con el lirismo fónico, sonoro y ruidista, las onomatopeyas imitativas e interpretativas, lenguajes inventados: cantos y voces alegres, estados de ánimo sorpresa, expresiones coloreadas y sintéticas sacadas de la vida, cotidianamente pulsante, mutable, con aspectos dramas, materias y maquinismos velozmente inagotables" ( [1934] 1987, 7). Estas líricas estaban dirigidas al sujeto contemporáneo y dinámico que se encuentra en cualquier lugar: "en la calle, en el café, en el aeroplano, sobre la cubierta de un barco, en mil atmósferas diversas" (ibíd., 8). Para el de Rovereto, la radio debía modificar el estado de ánimo del sujeto contemporáneo, su estado nervioso, a partir de la experiencia sonora.

\section{DE FRANCO CASAVOLA Y SILVIO MIX AL FUTURISMO MARCONIANO}

Los años del fascismo, en los que el movimiento artístico se identificó con la política del régimen, provocaron una pérdida de intensidad en las manifestaciones futuristas. Russolo, dedicado exclusivamente a la investigación ruidista diseñaría variables de sus intonarrumori en el rumorarmonio, combinación de las palabras rumore y armonio, con el que desarrollaría las seis familias de ruidos con un solo instrumento y el russofóno, pero desencantado y "envenenado de política, retórica, nacionalismo y guerra" (2017: 198) se trasladó a Cataluña en lo que suponía "un alejamiento de la máquina y de la urbe" (Ferré 2017, 206).

Las experiencias musicales del grupo futurista abandonaron paulatinamente el experimentalismo previo a favor de una música urbana ligada a una práctica escénica en la que destacarían Franco Casavola y Silvio Mix. Casavola escribió una serie de manifiestos ${ }^{5}$ que "ni por su fecha ni por las intenciones del autor, son manifiestos instauradores, a la manera de los publicados por Balilla Pratella o Luigi Russolo a comienzos de la década de los diez" (San Martin 1991, 273) entre los que destacaban Musica futurista (1924) -en el que hacía una defensa de la experiencia de Russolo ${ }^{6}$ - y Le Sintesi visive (1924) cofirmado con Luciani.

Entre sus composiciones futuristas destacaba la música para Festa di Piedigrotta (1923) inspirado en el libro homónimo de Cangiullo ${ }^{7}$, que combinaba instrumentos clásicos con instrumentos tradicionales napolitanos, Anihccam 
del 3000. Interpretazione e riproduzione dei movimienti e rumori delle macchine (1924) en el que musicalizó la obra de Depero la Fantasia meccanica per orchestra para la producción Tre momenti (1925) de Luciano Folgore -en el que se sirvió de los intonarumori para describir una obra sobre la civilización mecánica- y la partitura de la Danza dell'elica (1924) en la que insertaba en la orquesta un motor de explosión y una máquina de viento (Hulten 1992, 444). Casavola buscó crear una verdadera música futurista como extensión de los sonidos metropolitanos, pero romperá abruptamente con el movimiento y destruirá su obra vanguardista en 1927.

Silvio Mix (seudónimo de Silvio del Re) ligado a los grupos futuristas de Antonio Marasco en Florencia, partía de la destrucción de la cuadratura tradicional y la conquista enarmónica de Pratella y de la experiencia de los ruidos musicalizados de Russolo. El 19 de agosto de 1926 publicó en L'Impero Verso le nuove forme dell'arte musicale en el que pergeñó las líneas argumentales del futurismo musical como los "sonidos musicalizados" y las "superposiciones rítmico-plurizonales" a partir de "voces, instrumentos tradicionales, intonarrumori, ruidos, etc." Su obra más relevante fue Commenti sinfonici per "L'angoscia delle macchine", op. 70 (1927) una síntesis trágica en tres tiempos para la obra de Ruggero Vasari. Del mismo modo compuso música para el Teatro de la Pantomima futurista.

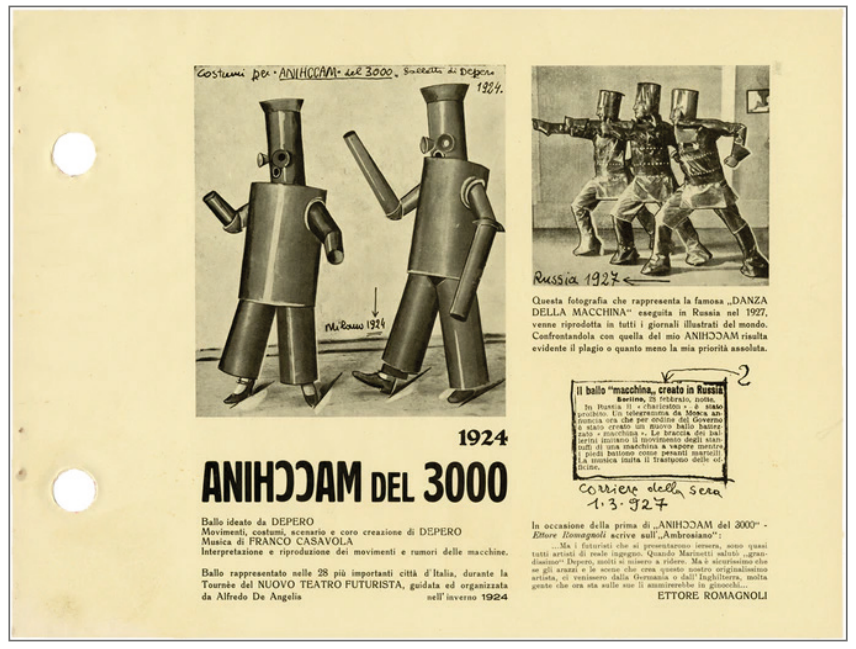

Fortunato Depero, Anihccam del 3000, 1924. Música de Franco Casavola.

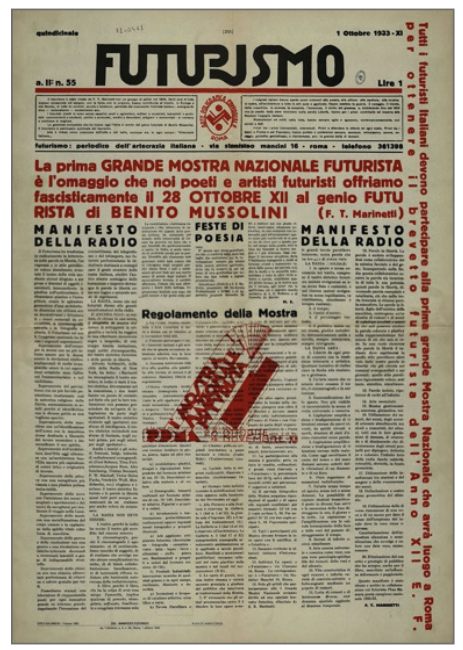

Pino Masnata y F. T. Marinetti. Manifesto della Radio. Futurismo, a. II, $\mathrm{n}^{\circ}$ 55,1 de octubre de 1933, Roma. 
Marinetti y Pino Masnata publicaron en octubre de 1933 La radia en la Gazzetta del Popolo, manifiesto en el que proponían soluciones acústicas en el mundo del arte y una "captación amplificada y transfiguración de vibraciones emitidas por vivos y muertos estados de ánimo ruidistas sin palabras" reconociendo que la abstracción y la inmaterialidad del nuevo medio superaba las convenciones clásicas de los formatos artísticos. Los ejemplos de radiofonía futurista aparecían representadas en cinco síntesis en las que articulaban ruidos, silencios e interferencias de los entornos metropolitanos: sonidos que se interrumpen abruptamente por otros en Los silencios hablan entre sí; Un paisaje oye que alternaba sonidos de agua y fuego; Drama de distancias, que reconstruía siete bloques de once segundos de una marcha militar en Roma, un tango bailado en Santos, música religiosa japonesa en Tokio, un baile campestre en la campiña de Varese, un combate de boxeo en Nueva York, ruidos de la calle en Milán y una canción napolitana cantada en el hotel Copacabana de Río de Janeiro y Batalla de ritmos síntesis que combinaba sonidos de elementos naturales y mecánicos en el entorno metropolitano. El silencio se convierte para los futuristas en la antítesis del ruido, continuando la línea argumental de Russolo y Carrà y La construcción de un silencio anunciaba las investigaciones de John Cage sobre el silencio en los años sesenta.

La primera transmisión de arte fonético fue realizada por Depero y Marinetti en la emisora Radio Milano el 24 de noviembre de 1928. En febrero de 1929, Marinetti declamó su Battaglia di Adrianopoli, una de las escasas radiotransmisiones futuristas que se conservan en una grabación de la productora milanesa Voce del Padrone y que constituye el final de las investigaciones sobre sonido y metrópoli del movimiento futurista.

Otras intervenciones se englobaban en el discutible epílogo que identifica al futurismo con el fascismo y en la que la aeropoesía se convirtió en una parte de las radiocrónicas belicistas. Marinetti declamó en la radio el retorno transcontinental de los hidroaviones de Italo Balvo en 1933. Las declamaciones y emisiones futuristas en tiempos de guerra fueron rechazadas por los oyentes por su experimentalidad y extravagancia. Las últimas intervenciones futuristas para el EIAR (Ente Italiano per le Audizione Radiofoniche) se redujeron a diez minutos: el máximo de poesía futurista que el público italiano podía soportar (Mancebo Roca 2004, 69). 


\section{CONCLUSIÓN}

El futurismo italiano fue la primera vanguardia que intentó aprehender los sonidos de las ciudades y reinterpretarlos como un elemento que destruiría la concepción pasadista de las grandes capitales estableciendo una praxis ruidista para terminar con el silencio tradicional. A partir de la superación de todos los simbolismos incluirían los ruidos y sonidos de la ciudad en sus composiciones. Russolo concebirá una música basada exclusivamente en los sonidos que recrearían y reconstruirían las resonancias de la ciudad que modificaría en composiciones de ruidos similares a aquellas clásicas. La poesía y los neolenguajes incorporarían el ruido del movimiento de las máquinas y, en la última fase del movimiento, el sonido urbano a través de las experiencias de los músicos de los diez se trasladaría a la época del retour à l'ordre. La incorporación de un arte de los ruidos fue una de las grandes aportaciones del futurismo italiano antes de su primera gran crisis creativa. Los experimentos de los futuristas fueron determinantes para las investigaciones musicales de la segunda vanguardia que, a partir de su legado, construyeron toda una teoría y práctica de la música experimental que se extiende hasta nuestros días.

\section{Referencias bibliográficas}

Alarcón Molina, Miguel, coord. 2004. Ruidos y susurros de las vanguardias: Reconstrucción de obras pioneras del arte sonoro (1909-1945). Laboratorio de Creaciones Intermedia. València: Universidad Politécnica de València

Bellorini, Giuliano, Anna Gasparotto \& Franco Tagliapietra. 2011. Luigi Russolo: La musica, la pittura, il pensiero; Nueve ricerche sugli scritti. Firenze: Olschki

Cangiullo, Francesco. (1923) 1979. Poesia pentagrammata. Firenze: SPES-Salimben

Carrà, Carlo. (1915) 1979. Guerra pittura: Futurismo politico, dinamismo plastico, 12 disegni guerreschi, parole in libertà. Firenze: SPES-Salimbeni

— . 1913. "La pittura dei suoni, rumori, odori: Manifesto futurista". https://www.wdl.org/es/ item/20040/view/1/1/

Casavola, Franco. (1924) 1991. "La música futurista". En La mirada nerviosa: Manifiestos y libros futuristas, Francisco Javier San Martín, ed., 274-6. Donostia-San Sebastián: Arteleku

Chessa, Luciano. 2012. Luigi Russolo, futurist noise, visual arts, and the occult. Berkeley CA: California University

Depero, Fortunato. (1934) 1987. Liriche radiofoniche. Firenze: SPES-Salimbeni

— . 2012. Ricostruire e meccanizzare I'Universo. Scritti racolti e curati da Giovanni Lista. Milán: Abscondità

Fanelli, Giovanni \& Ezio Godoli. 1988. Il futurismo e la grafica. Milán: Comunità 
Ferré, Xavier. 2017. "Luigi Russolo: Un elefante en Tarragona”. En ¡Chum, chum, pim, pam, pum, olé! Pioneros del arte sonoro en España, de Cervantes a Vanguardias, Miguel Molina Alarcón, coord., 194-206. València: Universidad Politécnica de València

Ghignoli, Alessandro. 2011. "Los lenguajes poéticos marinettianos en el Futurismo: De lo visual a lo sonoro". En Futurismo: La explosión de la vanguardia, Alessandro Ghignoli \& Llanos Gómez, dirs., 41- 55. Madrid: Vaso Roto

Hulten, Pontus. 1992. Futurismo \& Futurismi. Venezia: Bompiani

Lista, Giovanni \& Pablo Gianera. 2010. La conquista del ruido. La poética del Futurismo. Buenos Aires: Proa

Lista, Giovanni. 1984. Le libre futuriste: De la liberation du mot a u poéme táctile. Paris: Panini

- . 2009. Luigi Russolo e la musica futurista. Milán: Mudima

- . 2011. Le Futurisme: Création et avant-garde. Paris: L'Ameteur

Lombardi, Daniele. 2009. “Rumorarmonie...." En Futurismo: Velocità + Arte + Azione 19091920, Giovanni Lista \& Ana Masoero, eds., 365-9. Milán: Skira

— . 2009. Nueva enciclopedia del Futurismo musicale. Milán: Mudima

Maffina, Gian Franco. 1978. Luigi Russolo e l'arte dei rumori: Con tutti gli scritti musicali. Turín: Martano

Mancebo Roca, Juan Agustín. 2004. "La radio futurista". ADE Teatro 99: 66-71

Marinetti, Filippo Tommaso. 1968. Teoria e invenzione futurista. Milán: Mondadori

Molina Alarcón Miguel et al. 2004. Ruidos y susurros de las vanguardias: Reconstrucción de obras pioneras del Arte Sonoro (1909-1945). Laboratorio de Creaciones Intermedia. València: Universidad Politécnica de València

Pizza, Antonio. 2015. Las ciudades del futurismo italiano: Vida y arte moderno; Milán, París, Berlín, Roma (1909-1915). Barcelona: Universidad de Barcelona

Pratella, Francesco Balilla. 1910. Manifesto dei musicisti futuristi. Milán: Direzione del Movimiento Futurista

— . 1911. La música futurista: Manifesto técnico. Milán: Direzione del Movimiento Futurista

— . 1912. La distruzione della quadratura. http://futurismo.accademiadellacrusca.org/ immagine.asp?idscheda $=21 \&$ file_seq $=1$

— . 1920. El aviatore Dro: Poema tragico en tre atti. Milán: Casa Musicale Sonzogno. https:// teca.bncf.firenze.sbn.it/ImageViewer/servlet/ImageViewer?idr=BNCF00004449850

Russolo, Luigi. 1916. L'arte dei rumori. Milán: Edizione Futuriste di "Poesia"

Salaris, Claudia. 1992. Storia del Futurismo. Libri, giornali, manifesti. Roma: Riuniti

San Martín Martínez, Francisco Javier, ed. 1991. La mirada nerviosa: Manifiestos y textos futuristas. Con una intervención de Maurizio Scudiero. Donostia-San Sebastián: Arteleku

Solanas Jiménez, María del Carmen. 2011. La poética futurista. Madrid: Universidad Autónoma de Madrid

Tagliapietra, Franco \& Ana Gasparotto, eds. 2006. Luigi Russolo: Vita e opere di un futurista. Milán: Skira

\section{Discografía citada}

Musica futurista. Milan: Cramps Records, 1980. 2 CD-ROM. https://sonmarchive.es/index.php/ es/component/muscol/V/4931-v-v-a-a-musica-futurista/775-musica-futurista 
Musica futurista: The art of noises; music and words from the Italian Futurist Movement 19091935. Including original recordings by Marinetti, Russolo \& Pratella. Dereham UK: Salon LTM, 2004

Ruidos y susurros de las vanguardias: Reconstrucción de obras pioneras del Arte Sonoro (1909-1945). Valencia: Allegro Records, 2004. 2 CD-ROM https://www.upv.es/intermedia/ pages/laboratori/publicacions_produccions/2004_ruidos_y_susurros/produccions_ruidos_susurros_doble_cd_e.htm\#

\section{Notas}

${ }^{1}$ Carlo Carrà mencionaba explícitamente en el manifiesto que, por influencia del arte de los ruidos de Russolo, la pintura anterior al siglo XIX era el arte del silencio y que el futurismo, con la incorporación de ruidos, sonidos y olores, abría nuevos espacios de trabajo hacía una pintura total que exigiría la participación de todos los sentidos. Carrá afirmaba (1913, 2): "es indiscutible que $1^{\circ} \mathrm{el}$ sonido es estático y que los sonidos, ruidos y olores son dinámicos; $2^{\circ}$ sonidos, ruidos y olores no son otra cosa que diferentes formas de intensidad de vibración".

${ }^{2}$ Antonio Russolo ayudaría a Luigi en su investigación musical cuando abandonó la pintura y se decantó por el arte de los ruidos. Antonio fue discípulo de Arturo Toscanini y existen fotos de los hermanos en los conciertos con intonarumori de los años veinte.

${ }^{3}$ Attilio Teglio lo define en L'arte libera in Italia: La prima esposizione inaugurata a Milano el 4 de julio de 1911 en el "Giornale" de Bérgamo "[...] un músico espectral, un artista que se asemeja a Beethoven, está sentado al piano; sus manos se multiplican extrayendo del teclado una música guiada por la inspiración. En el aire se desanuda un largo flujo de cinta azul; y la onda de la melodía se desenvuelve y alarga a lo alto hasta el infinito. Un nimbo de círculos concéntricos denota las vibraciones de las ondas sonoras. Las notas, los sonidos, los acordes son convertidos en mascaras de la larga estela coloreada y cada una tiene un rostro especial. Cantando en alta y baja voz, ríen y sonríen, llora y gimen, gritan a veces, levando cada una su contribución en aquel complejo de sentimiento del cual resultara un todo sinfónico" (citado en Tagliapietra 2006, 26-7).

4 "Atravesemos una gran capital moderna, con las orejas más atentas que los ojos, y disfrutaremos distinguiendo los reflujos de agua, de aire o de gas en los tubos metálicos, el rugido de los motores que bufan y pulsan con una animalidad indiscutible, el palpitar de las válvulas, el vaivén de los pistones, las estridencias de las sierras mecánicas, los saltos del tranvía sobre los raíles, el restallar de las fustas, el tremolar de los toldos y las banderas. Nos divertiremos orquestando idealmente juntos el estruendo de las persianas de las tiendas, las sacudidas de las puertas, el rumor y el pataleo de las multitudes, los diferentes bullicios de las estaciones, de las fraguas, de las hilanderías, de las tipografías, de las centrales eléctricas y de los ferrocarriles subterráneos" (Russolo 1916, 12).

${ }^{5}$ La música dell'avvenire; La música ilustrata; Le versione scenoplastiche della musica; Le atmosfere cromatiche della musica (con Luciani y Bragaglia).

6 "Los ritmos incisivos precisan nuevos medios de expresión: máquinas y medios mecánicos, que no impliquen una inútil multiplicación de timbres orquestales, sino que se limiten a su tarea de percutores rítmicos. Con los intonarumori de Luigi Russolo, la orquesta se ha enriquecido con nuevas familias de instrumentos y una inagotable cantera de timbres originalísimos. Con el ruidismo puro de las máquinas señalamos las poderosas armaduras rítmicas de la música futurista" (Casavola [1924] 1991, 275). 
${ }^{7}$ Piedrigotta, publicado en 1916 por Francesco Cangiullo en las Edizioni futuriste di "Poesia", era un poemario parolibero inspirado en la homónima fiesta popular napolitana que se podía interpretar como una performance escrita, por lo que tuvo representaciones en la galería de Sprovieri en Roma. En volumen era "una obra maestra tipográfica es la interpretación polifónico- ruidista- onomatopéyica de la conocida fiesta popular: aquí el modernismo de la composición visual toma literalmente el fuego, alimentado por la vis cómica, histriónica, plebeya y cancionista del autor" (Salaris 1992, 107).

(Artículo recibido: 28-03-21; aceptado: 04-06-21) 